\title{
BMJ Open Prevalence of and factors associated with fewer than 20 remaining teeth in Taiwanese adults with disabilities: a community-based cross-sectional study
}

\author{
Mei-Yu Pan, ${ }^{1,2}$ Tsung-Cheng Hsieh, ${ }^{2}$ Hung-Cheng Tai, ${ }^{3}$ Ming-Shyan Lin, ${ }^{4}$ \\ Yu-Chen Lin, ${ }^{5}$ Mei-Yen Chen ${ }^{1,4,6}$
}

To cite: Pan M-Y, Hsieh T-C, Tai H-C, et al. Prevalence of and factors associated with fewer than 20 remaining teeth in Taiwanese adults with disabilities: a community-based cross-sectional study. BMJ Open 2017;7:e016270. doi:10.1136/ bmjopen-2017-016270

\section{- Prepublication history for} this paper is available online. To view these files please visit the journal online (http://dx.doi. org/10.1136/bmjopen-2017016270).

M-YP and T-CH contributed equally.

Received 3 February 2017 Revised 25 August 2017 Accepted 15 September 2017

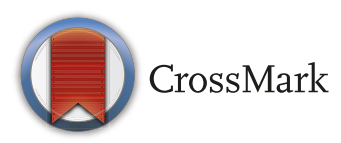

${ }^{1}$ Department of Nursing, Chang Gung University of Science and Technology, Chiayi, Taiwan ${ }^{2}$ Institute of Medical Sciences, Tzu Chi University, Hualien, Taiwan

${ }^{3}$ Department of General Education, Chang Gung University of Science and Technology, Chiayi, Taiwan ${ }^{4}$ Department of Cardiology, Chang Gung Memorial Hospital, Chiayi, Taiwan

${ }^{5}$ Department of Health

Promotion, Chiayi Bureau of Health, Taiwan

${ }^{6}$ Department of Nursing, Chang Gung University, Taoyuan, Taiwan

Correspondence to

Mei-Yen Chen;

meiyen@mail.cgust.edu.tw

\section{ABSTRACT}

Objectives To examine the prevalence of and the factors associated with a number of remaining teeth (NRT) $<20$ among adults with disabilities.

Design A community-based, cross-sectional descriptive study.

Setting This study was part of a health promotion programme designed for community-dwelling adults with disabilities.

Participants A total of 549 adults with disabilities, aged 20-80 years, living in the community in Chiayi County in Taiwan.

Outcome measures Various parameters, including NRT, oral health behaviours (ie, oral hygiene, dietary habits and substance use), comorbidities, disability classification and capability for performing activities of daily living, were measured. Data were statistically analysed using descriptive statistics and multivariate logistic regression analysis.

Results The mean NRT was 18.1 (SD=10.9); $44.8 \%$ of participants had NRT $<20$ (including $13.7 \%$ edentulous participants). Most participants had poor oral hygiene: $83.4 \%$ reported seldom using dental floss, $78 \%$ did not undergo regular 6-monthly dental check-ups and $77.4 \%$ seldom brushed their teeth after meal. After adjusting for potentially confounding variables, the intellectual disability group had a significantly higher risk of an NRT $<20$ than the physical disability group (OR $2.30,95 \% \mathrm{Cl}$ 1.30 to 4.08). Additionally, the rare use of dental floss and hypertension significantly increased the possibility of an NRT $<20$ (OR 1.73-2.12, 95\% Cl 1.15 to 3.71 ).

Conclusions An NRT $<20$ and edentulism were highly prevalent among adults with disabilities, who displayed poor oral hygiene behaviours. Adults with intellectual disabilities had a greater likelihood of having an NRT $<20$ than did those with physical disability. In addition to unmodifiable factors, the poor use of dental floss was significantly associated with an NRT $<20$.

\section{INTRODUCTION}

Having 20 teeth or more helps adults maintain good oral function and overall health. Teeth are recognised as calcified structures in the mouth, with the primary purpose of

\section{Strengths and limitations of this study}

- Few studies have reported the prevalence of and factors associated with few remaining teeth among adults with disabilities, particularly in those residing in communities.

- These results highlight the value of nurse-led health promotion programmes and implementation of a multidisciplinary approach for the early detection of a low number of remaining teeth in communitydwelling adults with disabilities.

- The limitations of the study include the nonrandomised sampling strategy and recruitment of individuals with disabilities that did not preclude mobility in coming to the examination centre, which may hinder generalisation of our findings.

- Other shortcomings regarding self-reported and/or caregiver-reported behaviours are social desirability, and the recall process might involve biases due to poor memory retrieval.

mastication, but act as part of the broader digestive system, to help the body obtain nutrition. $^{1-3}$ Other key functional aspects of teeth include speaking and communication, facial appearance, facilitating interpersonal relationships, enhancing quality of life, systemic health and cognitive function; teeth are also associated with disability status and even with mortality. ${ }^{3-6}$ Unfortunately, 3.9 billion individuals worldwide experience oral disorders, including untreated caries, severe periodontal disease and severe tooth loss, thereby prolonging the years lived with disability. ${ }^{4}$ In fact, as early as 1991, Japan conducted a series of oral campaigns called the ' 8020 ' to encourage citizens to maintain at least 20 remaining teeth through the age of $80 .^{3}$ Previous studies on elderly people also proved that the lower the number of remaining teeth (NRT), the greater the impacts on individuals' health. These impacts include the higher risks of cognitive impairments, 
decreased self-care capabilities, heart rate acceleration, influences on the quality of life and decreased cumulative survival rate. ${ }^{13}$ NRT has become an important indicator of oral and overall health for adults.

Awareness of the factors associated with an NRT $<20$ forms the basis for good oral care. Of all the risk factors for an NRT $<20$, age is probably the primary factor, ${ }^{7-10}$ but it is not a controllable or reversible factor, neither are sex and education. ${ }^{10-12}$ Therefore, public health professionals concentrate on risk factors that can be modified. Other factors associated with tooth loss include hypertension, diabetes mellitus, hyperlipidaemia, poor oral hygiene, unhealthy diet, smoking and harmful alcohol consumption, ${ }^{1011} 13-15$ but those that are specific for individuals with disabilities remain unclear.

The oral health condition of disabled individuals is often worse than that of non-disabled adults. ${ }^{2}{ }^{16-23} \mathrm{Util}-$ isation of oral health services is also far lower than the average for this group. ${ }^{161724}$ WHO has warned that, as the population ages and chronic diseases increase, there will be an increase in the rate of disability. Currently, more than a billion people worldwide $(15 \%)$ live with some form of disability, with $2 \%-4 \%$ of those over the age of 15 years having significant difficulties in functioning. In addition, due to poverty and difficulties with mobility, the disabled are particularly vulnerable in terms of accessing satisfactory healthcare services. They are also more likely to engage in risky health behaviours and to be affected by more complications, more comorbidities, faster degeneration and earlier mortality. ${ }^{25}$ In Taiwan, there are more than 1.1 million people with disabilities $(4.8 \%$ of the population). ${ }^{26}$ Research has shown that disabled adults rarely use oral health services, ${ }^{27}$ even though the government has already increased their oral care services. These premium subsidies funded by the National Health Insurance (NHI) system include use of fluoride gel/ varnishes, more frequent dental scaling and a bonus for the dentists treating patients with specific disabilities. ${ }^{28} \mathrm{In}$ terms of human rights, preventing the increase in levels of disability, as well as reducing the caregivers' burdens, which are issues relating to oral healthcare for vulnerable groups, deserve much attention.

However, although some previous studies have focused on institution-accommodated adults with disabilities, ${ }^{2} 18$ fewer reports have discussed disabled individuals living in communities. The prevalence of NRT $<20$ and factors potentially relevant to oral health among non-institutional disabilities were also seldom discussed. Therefore, the aims of this study were to explore the prevalence of and factors associated with an NRT $<20$ among community-dwelling adults with disabilities in Taiwan and to explore the oral health behaviours among the participants.

\section{METHODS}

\section{Design, sample and setting}

This study, which was part of a second-year health promotion programme designed for community-dwelling adults with disabilities, was led by a nursing team in collaboration with a district hospital and the Bureau of Health Promotion of Chiayi County in Taiwan. ${ }^{25}$ In Chiayi County, visual impairment, hearing impairment, intellectually disability and physical disability affect more than 38800 individuals, accounting for $64 \%$ of the local disabled population. This paper forms part of a series of reports regarding health issues of community-based people with disabilities. A community-based health screening survey was conducted between July and December in 2014 using a cross-sectional descriptive design.

Participants were selected through convenience sampling from the registry of the government's social welfare centre. ${ }^{21}$ The inclusion criteria were: (1) certified adults' primary disability, involving either visual impairment, hearing impairment, intellectual disability or physical disability; (2) age $\geq 20$ years; (3) the ability to complete the written questionnaire in either Mandarin or Taiwanese, with assistance from the interviewers; (4) the ability to walk to the examination centre with/without help and (5) the ability to sign the consent forms prior to recruitment. Exclusion criteria were: (1) living in institutions; (2) an inability to answer questions or (3) having a serious disease, such as kidney disease requiring dialysis or cancer.

\section{Measurements}

Number of remaining teeth

The NRT was obtained by research assistants by asking the participants to open his/her mouths and then counting the total number of natural teeth and fixed dentures, after discharging the removable dentures in the oral cavities. Root fragments without a crown were excluded. As edentulism is an alternative measure of oral health status, ${ }^{29}$ it was distinguished as an outcome to present a fuller picture of NRT. Thus, three categories, edentulous $(\mathrm{NRT}=0)$, less-dentate $(\mathrm{NRT}=1-19)$ and more-dentate (NRT $\geq 20)$ were defined. The edentulous and less-dentate groups are referred to as those with fewer teeth $($ NRT $<20)$.

\section{Oral health behaviours}

Oral health behaviours were measured in terms of seven habits, that is, brushing teeth, using dental floss, visiting dentists or undergoing dental scaling, drinking alcohol, smoking, five groups of nutrition and water intake. This information was collected through standardised personal interviews using a structured questionnaire that was based on the published literature. ${ }^{710}$ The participants were asked to recall their oral health behaviours up to a year previously and/or when they were dentate.

In this study, answers regarding the brushing of teeth were categorised as frequent ( $\geq$ two timesa day) versus infrequent $(<$ two times a day). As for immediate brushing teeth after a meal, participants were classified as 'often' if they responded with 'usually' or 'frequently' or 'seldom' if they responded with 'never' or 'sometimes'. For using dental floss, responses were classified as 'often' if dental 
floss was used to clean interdental spaces one or more timesa day or 'seldom' if the respondents' answer was 'never' or 'sometimes.' Regarding visits to dentists, participants were classified as 'regular' if they visited dentists and underwent scaling every 6 months or 'irregular' if they responded 'never' or 'sometimes.' For questions 'Do you smoke cigarettes or drink alcohol?', participants were classified as 'none or formerly' if they had never engaged in these behaviours or had stopped doing so for the past year, or as 'current users.' Regarding five groups of nutrition intake, the response was considered 'balanced' if the respondents usually or always had five groups of nutrition (ie, meat, milk, grains, vegetables and fruit) each day or 'unbalanced' if they never or sometimes had these foods. In terms of water intake, answers were categorised as sufficient $(\geq 1500 \mathrm{~mL}$ per day) versus insufficient $(<1500 \mathrm{~mL}$ per day). Participants, especially those intellectual and hearing disabled, were guided to reply their habits through visual aids, samples, progressive interactions and caregivers' confirmations when necessary.

\section{Background information}

Background information comprised three sections. First, demographic variables obtained from the questionnaires, including age, gender and educational attainment (years of education received or level of school completed). Second, prevalence of the three common chronic diseases (ie, hypertension, diabetes mellitus and hyperlipidaemia). The three diseases were assessed using a medical history (diagnosed by a physician) and/or physiological biomarkers, including blood pressure (BP), fasting blood glucose (FBG), triglyceride (TG), total cholesterol (TC), low-density lipoprotein (LDL) cholesterol and high-density lipoprotein cholesterol levels. Following the national standard of the Ministry of Health and Welfare, ${ }^{30}$ blood samples were evaluated and BP was measured at the time of the study, applying standard procedures. The three common chronic diseases were defined as (1) diabetes mellitus ( $\mathrm{FBG} \geq 126 \mathrm{mg} / \mathrm{dL}$ or if ever diagnosed by a doctor); (2) hypertension (systolic/ diastolic $\mathrm{BP} \geq 140 / 90 \mathrm{~mm} \mathrm{Hg}$ or if ever diagnosed by a doctor) and (3) hyperlipidaemia (LDL $\geq 160 \mathrm{mg} / \mathrm{dL}$, $\mathrm{TC} \geq 240 \mathrm{mg} / \mathrm{dL}, \mathrm{TG} \geq 200 \mathrm{mg} / \mathrm{dL}$ or if ever diagnosed by a doctor). Third, disability classification and capability of activity of daily living (ADL). Primary disabilities, such as physical, hearing, vision or intellectual disabilities, were identified and confirmed by the certificates issued by the Taiwan government ${ }^{26}$ prior to the interviews. ADL capability, judged using the Barthel ADL Index of feeding, grooming, bathing, mobility, toilet use, transfer and so on reflected the dependence level of participants who required external assistance to complete these activities. 'Independent' was coded if external assistance was unnecessary or 'dependent' if it was needed.

\section{Procedures and ethical considerations}

This study was approved by the relevant institutional review board of Chang Gung Memorial Hospital (IRB
102-3331B), and all procedures complied with the ethical guidelines. Participants were invited to participate in the study via letters sent by the public health nurses and were fully informed about the purposes of the study. The letter emphasised the confidentiality of all collected data. Written consent forms were appropriately explained to and signed by participants and/or their guardians before arranging free medical evaluations. These evaluations, including blood sampling and physical check-ups, were conducted by the local hospital staff on a weekend, in a school auditorium, followed by individual interviews. To create a caring and friendly environment, each participant was accompanied by a community volunteer during the health screenings. If a participant was not an effective responder, a familiar caregiver, who was normally a family member(s) with whom they were living, was allowed to represent the participant in answering the questions.

The NRT was calculated carefully by research assistants who were trained by a research team that including the investigators and a dentist. Details of the interviews and measurement procedures have been reported in our previous study. ${ }^{10}$ Face and content validity of the instrument were judged to be good $(0.88-0.91)$ by a panel of five experts: a faculty member in public health and health education, a dentist, a social worker in a disabled institution and two nursing faculty members who specialise in the field of long-term care.

\section{Statistical analyses}

Quantitative data were analysed using SPSS V.22.0 software. Descriptive statistical data are presented as numbers and percentages for categorical variables and as means \pm SDs for continuous variables. $\chi^{2}$ tests for categorical variables, as univariate analyses, were performed to compare those in the edentulous (NRT $=0)$, less-dentate (NRT $=1-19)$ and more-dentate (NRT $\geq 20$ ) groups in terms of their background information and oral health behaviours. Stepwise logistic regression analyses, for identifying the modifiable factors associated with having fewer teeth $($ NRT $<20)$, were conducted in three models. The first model, model 1, a crude model without adjustment, was used to examine the associations between exposures and NRT $<20$. The second, model 2, was partially adjusted, for three irreversible confounding factors, including age, gender and education. The third, model 3 , was fully adjusted for all exposures in the current study. For models 2 and 3, multivariable logistic regression analysis with a forward variable entry method (entry criteria: p Value $<0.05$ in univariate analysis) was implemented. The OR with $95 \%$ CI and corresponding p Value were obtained by logistic regression model. All statistical assessments adopted two-tailed tests, and the $p$ Value cut-off point for statistical significance was set as 0.05 .

\section{Results}

Of the 603 individuals invited to participate in the study, 549 participants were enrolled in this analysis, but 18 failed to complete the NRT measurement. The response 
Table 1 Background information of the subjects, according to dentition status

\begin{tabular}{|c|c|c|c|c|}
\hline \multirow[b]{3}{*}{ Variables } & \multicolumn{2}{|c|}{ Dentate* $^{*}$} & \multirow{2}{*}{$\begin{array}{l}\text { Edentulous* } \\
\text { NRT: } 0\end{array}$} & \multirow[b]{2}{*}{ Total } \\
\hline & NRT: $\geq 20$ & NRT: $1-19$ & & \\
\hline & $(n=293)$ & $(n=165)$ & $(n=73)$ & $(n=549)$ \\
\hline Age (years) $\dagger$ & $53.8 \pm 13.3$ & $63.1 \pm 12.4$ & $69.5 \pm 8.1$ & $58.8 \pm 13.9$ \\
\hline$<65$ & $228(77.8)$ & $81(49.1)$ & $13(17.8)$ & $331(60.3)$ \\
\hline$\geq 65$ & $65(22.2)$ & $84(50.9)$ & 60 (82.2) & $218(39.7)$ \\
\hline \multicolumn{5}{|l|}{ Gender } \\
\hline Female & $123(42.0)$ & $83(50.3)$ & $38(52.1)$ & $251(45.7)$ \\
\hline Male & $170(58.0)$ & $82(49.7)$ & $35(47.9)$ & $298(54.3)$ \\
\hline \multicolumn{5}{|l|}{ Educational attainment $†$} \\
\hline$>9$ years & $132(45.1)$ & $37(22.4)$ & $6(8.2)$ & $179(32.6)$ \\
\hline$\leq 9$ years & $161(54.9)$ & $128(77.6)$ & $67(91.8)$ & $370(67.4)$ \\
\hline \multicolumn{5}{|l|}{ Hypertension† } \\
\hline No & $154(52.6)$ & $54(32.7)$ & $23(31.5)$ & $239(43.5)$ \\
\hline Yes & $139(47.4)$ & $111(67.3)$ & $50(68.5)$ & $310(56.5)$ \\
\hline \multicolumn{5}{|l|}{ Diabetes mellitus $†$} \\
\hline No & $235(80.2)$ & $121(73.3)$ & $47(64.4)$ & $418(76.1)$ \\
\hline Yes & $58(19.8)$ & $44(26.7)$ & $26(35.6)$ & $131(23.9)$ \\
\hline \multicolumn{5}{|l|}{ Hyperlipidaemia } \\
\hline No & $138(47.1)$ & $88(53.3)$ & $37(50.7)$ & $275(50.1)$ \\
\hline Yes & $155(52.9)$ & $77(46.7)$ & $36(49.3)$ & $274(49.9)$ \\
\hline \multicolumn{5}{|l|}{ Disability classification } \\
\hline Physical disability & $166(56.7)$ & $93(56.4)$ & $38(52.1)$ & 307 (55.9) \\
\hline Intellectual disability & $64(21.8)$ & $32(19.4)$ & $8(11.0)$ & $108(19.7)$ \\
\hline Hearing impairment & $44(15.0)$ & $22(13.3)$ & 17 (23.3) & $86(15.7)$ \\
\hline Vision impairment & $19(6.2)$ & 18 (10.9) & $10(13.7)$ & $48(8.7)$ \\
\hline \multicolumn{5}{|l|}{ Capability of ADL* } \\
\hline Independent & $263(89.8)$ & $148(89.7)$ & 32 (84.9) & $486(88.7)$ \\
\hline Dependent & 30 (10.2) & $17(10.3)$ & $11(15.1)$ & 62 (11.3) \\
\hline
\end{tabular}

Data are expressed as numbers (percentages) or means \pm SDs.

*Missing data: 1 in ADL, 18 in NRT.

$\dagger \mathrm{p}<0.05$ derived from $\chi^{2}$ tests.

$A D L$, activities of daily living; NRT, number of remaining teeth.

rate was therefore $91 \%$. The majority of the participants were men $(54.3 \%)$, aged $20-80$ years (mean age $58.8 \pm 13.9$ ), and were not well educated (educational attainment $\leq 9$ years: $67.4 \%$ ). The distribution of disabilities by type was: physical $(55.9 \%)$, intellectual $(19.7 \%)$, hearing $(15.7 \%)$ and vision $(8.7 \%)$. Most participants $(88.7 \%)$ did not require assistance in the activities of daily living (ADL), as they only had a mild degree of disability. In addition, the prevalence rates of hypertension, hyperlipidaemia and diabetes mellitus were $56.5 \%, 49.9 \%$ and $23.9 \%$, respectively. Moreover, $\chi^{2}$ tests results indicated that participants who were of older age, had lower education, and had histories of hypertension and/or diabetes had significantly greater likelihoods of having fewer teeth and/or edentulous (table 1).
As shown in table 2, the participants had fewer teeth (mean NRT 18.1 \pm 10.9 ; median 21.0; NRT <20: $44.8 \%$; NRT $=0: 13.7 \%$ ) and had poor oral hygiene (seldom dental floss: $83.4 \%$; irregular dental visit: $78.0 \%$; seldom brushed teeth after meal: $77.4 \%$; daily teeth brushing: $1.8 \pm 0.9$ times). They also had other unfavourable behaviours (insufficient water intake/unbalanced nutrition: $40.3 \%$; smoking: $25.3 \%$; drinking alcohol: $16.2 \%) \cdot \chi^{2}$ test results showed that participants with the characteristics of rare dental floss use, irregular dentist visits or unbalanced nutrition had a significantly higher prevalence of having fewer and/or no teeth.

Regarding table 3, after adjusting for all exposures (in model 3), the intellectual disability group had a significantly higher possibility of an NRT $<20$ than the physical 
Table 2 Number of remaining teeth and oral health behaviours according to dentition status

\begin{tabular}{|c|c|c|c|c|}
\hline \multirow[b]{3}{*}{ Variablest } & \multicolumn{2}{|c|}{ Dentate* $^{*}$} & \multirow{2}{*}{$\begin{array}{l}\text { Edentulous }{ }^{*} \\
\text { NRT: } 0\end{array}$} & \multirow[b]{2}{*}{ Total } \\
\hline & NRT: $\geq 20$ & NRT: 1-19 & & \\
\hline & $(\mathrm{n}=293)$ & $(n=165)$ & $(n=73)$ & $(n=549)$ \\
\hline Group of NRT $(n=531)^{*}$ & $26.7 \pm 3.7(27.0)$ & $10.8 \pm 5.5(12.0)$ & - & $18.1 \pm 10.9(21.0)$ \\
\hline 0 & & & & $73(13.7)$ \\
\hline $1-19$ & & & & $165(31.1)$ \\
\hline$\geq 20$ & & & & $293(55.2)$ \\
\hline \multicolumn{5}{|l|}{ Oral hygiene } \\
\hline Times of daily brushing teeth & & & & $1.8 \pm 0.9$ \\
\hline Frequent ( $\geq 2$ times) & 204 (69.5) & $116(70.3)$ & $44(60.3)$ & $372(67.8)$ \\
\hline Infrequent (<2 times) & $89(30.4)$ & $49(29.7)$ & $29(39.7)$ & $177(32.2)$ \\
\hline \multicolumn{5}{|l|}{ Brushing teeth after meal } \\
\hline Often & $62(21.2)$ & $37(22.4)$ & $22(30.1)$ & $124(22.6)$ \\
\hline Seldom & $231(78.8)$ & $128(77.6)$ & $51(69.9)$ & $425(77.4)$ \\
\hline \multicolumn{5}{|l|}{ Using dental floss $\ddagger$} \\
\hline Often ( $\geq$ oncea day) & 67 (22.9) & $17(10.3)$ & 7 (9.6) & $91(16.6)$ \\
\hline Seldom (<oncea day) & $226(77.1)$ & $148(89.7)$ & $66(90.4)$ & $458(83.4)$ \\
\hline \multicolumn{5}{|l|}{ Visiting dentist per 6 months $\ddagger$} \\
\hline Regular & $73(24.9)$ & $38(23.0)$ & $7(9.6)$ & $121(22.0)$ \\
\hline Irregular & $220(75.1)$ & $127(77.0)$ & $66(90.4)$ & $428(78.0)$ \\
\hline \multicolumn{5}{|l|}{ Water intake per day } \\
\hline Sufficient $(\geq 1500 \mathrm{~mL})$ & $186(63.5)$ & $98(59.4)$ & 35 (47.9) & $328(59.7)$ \\
\hline Insufficient (<1500 mL) & $107(36.5)$ & $67(40.6)$ & $38(52.1)$ & $221(40.3)$ \\
\hline \multicolumn{5}{|l|}{ Five nutrition groups per day } \\
\hline Balanced & $191(65.2)$ & $84(50.9)$ & $47(64.4)$ & $328(59.7)$ \\
\hline Unbalanced & $102(34.8)$ & $81(49.1)$ & $26(35.6)$ & $221(40.3)$ \\
\hline \multicolumn{5}{|l|}{ Smoking habit } \\
\hline Never or formerly & $218(74.4)$ & $126(76.4)$ & $53(72.6)$ & $410(74.7)$ \\
\hline Current users & $75(25.6)$ & 39 (23.6) & $20(27.4)$ & $139(25.3)$ \\
\hline \multicolumn{5}{|l|}{ Alcohol habit } \\
\hline Never or formerly & $245(83.6)$ & $139(84.2)$ & 63 (86.3) & $460(83.8)$ \\
\hline Current users & $48(15.4)$ & $26(15.8)$ & $10(13.7)$ & 89 (16.2) \\
\hline
\end{tabular}

Data are expressed as numbers (percentages) or means \pm SDs (medians).

*18 missing data.

†All variables except NRT asked the edentulous subjects to recall their behaviours when dentate. $\neq \mathrm{p}<0.05$ derived from $\chi^{2}$ test.

NRT, number of remaining teeth.

disability group (OR 2.30, 95\% CI 1.30 to 4.08 ), while the risk of an NRT $<20$ in the other two subgroups were not increased. From the results of three models, that is, model 1 , model 2 and model 3 , the demographic variables seemed to confound an NRT $<20$ associated with disability classifications. The other modifiable factors associated with an NRT $<20$ were the rare use of dental floss (OR 2.12-2.64, 95\% CI 1.21 to 4.37 ) and a history of hypertension (OR 1.61-2.32, 95\% CI 1.09 to 3.31).

To exempt the risk of over adjustment, further analyses of correlations between three variables of hypertension, diabetes and hyperlipidaemia were done as they are common comorbidities. Weak correlations were identified $(r=0.11-0.16, p>0.05$, not shown in tables $)$ and so they did not influence model 3.

\section{DISCUSSION}

This study featured a nurse-led health programme aimed at promoting the oral health of disabled individuals. Four key findings emerged: first, fewer teeth were counted and there was a higher prevalence of an NRT $<20$ and edentulism in the present study population than in those reported in the existing literature. According to previous research, 
Open Access

Table 3 ORs $(95 \% \mathrm{Cl})$ of the factors associated with NRT $<20(\mathrm{n}=531 \dagger)$

\begin{tabular}{|c|c|c|c|}
\hline & Model 1 & Model 2 & Model 3 \\
\hline Variables/values & OR $(95 \% \mathrm{Cl})$ & OR $(95 \% \mathrm{Cl})$ & OR $(95 \% \mathrm{Cl})$ \\
\hline Age (years) & $1.08(1.06 \text { to } 1.09)^{\star}$ & $1.07(1.05 \text { to } 1.08)^{*}$ & $1.07(1.05 \text { to } 1.10)^{*}$ \\
\hline \multicolumn{4}{|l|}{ Gender } \\
\hline \multicolumn{4}{|l|}{ Femaleł } \\
\hline Male & $0.70(0.50 \text { to } 0.99)^{\star}$ & $\S$ & $\S$ \\
\hline \multicolumn{4}{|l|}{ Educational attainment } \\
\hline \multicolumn{4}{|l|}{$>9$ years $\ddagger$} \\
\hline$\leq 9$ years & $3.72(2.49 \text { to } 5.56)^{\star}$ & $2.01(1.28 \text { to } 3.14)^{*}$ & $1.96(1.23 \text { to } 3.10)^{\star}$ \\
\hline \multicolumn{4}{|l|}{ Hypertension } \\
\hline Noł & - & - & - \\
\hline Yes & $2.32(1.62 \text { to } 3.31)^{*}$ & $1.61(1.09 \text { to } 2.39)^{*}$ & 1.73 (1.15 to 2.60$)^{\star}$ \\
\hline \multicolumn{4}{|l|}{ Diabetes mellitus } \\
\hline Noł & - & - & - \\
\hline Yes & $1.69(1.13 \text { to } 2.52)^{*}$ & $\S$ & $\S$ \\
\hline \multicolumn{4}{|l|}{ Hyperlipidaemia } \\
\hline Noł & - & - & - \\
\hline Yes & 0.81 (0.57 to 1.13$)$ & $\S$ & $\S$ \\
\hline \multicolumn{4}{|l|}{ Disability classification } \\
\hline Physical disability $\ddagger$ & - & - & - \\
\hline Intellectual disability & 0.79 (0.50 to 1.25$)$ & $2.20(1.26 \text { to } 3.84)^{*}$ & $2.30(1.30 \text { to } 4.08)^{\star}$ \\
\hline Hearing impairment & 1.12 (0.69 to 1.83$)$ & 0.76 (0.44 to 1.32$)$ & 0.75 (0.43 to 1.32$)$ \\
\hline Vision impairment & 1.87 (0.99 to 3.49 ) & 1.54 (0.75 to 3.13$)$ & 1.48 (0.72 to 3.04$)$ \\
\hline \multicolumn{4}{|l|}{ Capability of ADL } \\
\hline Independent $\ddagger$ & - & - & - \\
\hline Dependent & 1.17 (0.68 to 2.02$)$ & $\S$ & $\S$ \\
\hline \multicolumn{4}{|l|}{ Oral health behaviours } \\
\hline \multicolumn{4}{|l|}{ Daily brushing teeth } \\
\hline Frequentł & - & - & - \\
\hline Infrequent & $1.12(0.77$ to 1.61$)$ & $\S$ & $\S$ \\
\hline \multicolumn{4}{|l|}{ Using dental floss } \\
\hline Often $\ddagger$ & - & - & - \\
\hline Seldom & $2.64(1.60 \text { to } 4.37)^{\star}$ & $2.22(1.28 \text { to } 3.83)^{*}$ & $2.12(1.21 \text { to } 3.71)^{\star}$ \\
\hline \multicolumn{4}{|l|}{ Visiting dentist } \\
\hline Regularł & - & - & - \\
\hline Irregular & $1.42(0.94$ to 2.16$)$ & $\S$ & $\S$ \\
\hline \multicolumn{4}{|l|}{ Water intake } \\
\hline Sufficientł & - & - & - \\
\hline Insufficient & 1.37 (0.97 to 1.95$)$ & $\S$ & $\S$ \\
\hline \multicolumn{4}{|c|}{ Five nutrition groups per day } \\
\hline Balanced $\neq$ & - & - & - \\
\hline Unbalanced & $1.53(1.08 \text { to } 2.17)^{*}$ & $1.58(1.07 \text { to } 2.34)^{*}$ & $\S$ \\
\hline \multicolumn{4}{|l|}{ Smoking habit } \\
\hline Never or formerly $\ddagger$ & - & - & - \\
\hline Current users & $0.96(0.65$ to 1.42$)$ & $\S$ & $\S$ \\
\hline
\end{tabular}


Table 3 Continued

\begin{tabular}{clll}
\hline & Model 1 & Model 2 & Model 3 \\
\cline { 2 - 4 } Variables/values & OR $(95 \% \mathbf{C l})$ & OR (95\% Cl) & OR (95\% Cl) \\
\hline Never or formerly & - & - & $\S$ \\
\hline Current users & $0.91(0.57$ to 1.46$)$ & $\S$ & $\S$ \\
\hline
\end{tabular}

Model 1: crude; model 2: adjusted for age, gender and education; model 3: model 2+all variables in this table.

${ }^{*} \mathrm{p}$ Value $<0.05$

†18 missing data.

$\ddagger$ Reference group.

§Variables were not selected into the model.

IVariables reflects edentulous subjects' recall of their behaviours when dentate.

ADL, activities of daily living; NRT, number of remaining teeth.

the average NRT for non-disabled people is approximately $25,{ }^{10}$ and only $16 \%$ of these individuals have an NRT $<20 .{ }^{210}$ However, in this study, the average NRT in disabled individuals was 18.1 and $44.8 \%$ had an NRT $<20$, which indicated a significantly worse oral health condition. Even when ruling out the edentulous, the average NRT was 20.9 and prevalence of NRT $<20$ was $36 \%$ among the dentate subgroup. The slight changes in the statistics from $18.1 \%$ to $20.9 \%$ and $44.8 \%$ to $36 \%$ do not indicate a change in the trend. The literature supports the view that adults with disabilities commonly exhibit poor oral hygiene and have a lower NRT than non-disabled people, owing to their limited capabilities, in terms of cognitive comprehension, body coordination or muscle power. ${ }^{11} 19$ In fact, the prevalence of an NRT $<20$ in this study was higher than the figures previously reported for non-disabled people, and also higher than that reported in a Belgian study of people with disabilities $(33 \%) .^{2}$ Moreover, the edentulous rate of $13.7 \%$ found in this study was also higher than the edentulous rate of $8.9 \%$ reported by a study conducted in the USA. ${ }^{16}$

Second, most disabled participants reported having inadequate oral hygiene behaviours in general. These behaviours, including seldom using dental floss, irregular dental visits and scaling, and rarely brushing teeth after meals, were factors associated with tooth loss in previous reports, ${ }^{178}$ and may also affect other systemic diseases. ${ }^{5}$ The prevalence of these behaviours in this study was $83.4 \%$, $78 \%$ and $77.4 \%$, respectively, which was much higher than in the non-disabled population (about 28\%-70\%) ${ }^{71015-17}$ and were also greater than those in disabled individuals in other countries $(29 \%-51 \%) .{ }^{16}{ }^{24}$ Particularly, those who were edentulous had worse oral hygiene behaviours than those who were dentate. Although irregular dental visits were not a significant factor for an NRT $<20$ in the current study, most previous studies indicated the importance of regular dental care. ${ }^{123132}$ To encourage regular dental care, the Taiwanese government has provided incentives under the NHI system, by requiring only payment of a registration and copayment fee, for use of oral health services by the disabled. ${ }^{28}$ However, individuals with disabilities typically do not visit dentists until their dental problems become too serious to be treated, and tooth extraction is often unavoidable. The issue of regular dental visits to help maintain a greater number of teeth in the disabled should be explored in future.

Third, adults with intellectual disability have an increased possibility of having an NRT $<20$. In this study, the extreme case, that is, edentulous, showed a prevalence of $7.7 \%$ among those with intellectual disability, which was lower than that reported in the USA $(10.9 \%){ }^{22}$ In comparison with those with physical disability, the subgroup of individuals with intellectual disabilities had a higher likelihood of having fewer teeth, which is consistent with the findings of previous studies. ${ }^{291822}$ Lindsay $^{33}$ attributes this phenomenon to their preferences for eating desserts, sweets and drinking soft drinks; similarly, their reduced capacity for self-control owing to their cognitive impairments could also modulate this effect. These individuals often are not fully capable of independent self-care, and their caregivers may find it difficult to perform oral hygiene activities for them over the long term. In addition, adults with developmental disabilities often appear to have disorders, such as gastro-oesophageal reflux disease, excessive salivation and induced xerostomia triggered by antiepileptic medications, which could increase the possibility of poor oral health.

Fourth, the use of dental floss is a modifiable factor associated with the NRT. Except for intellectual disabilities, other associated factors, such as the rare use of dental floss and hypertension ${ }^{1} 1013$ are similar to the factors associated with NRT in non-disabled individuals. Among these, dental floss use is the most malleable component that can be addressed by instruction from public health practitioners. This study found that most disabled adults (77.4\%) lacked the habit of cleaning teeth after meals and brushed their teeth less often than two times a day. The practice of dental flossing may be a complementary oral hygiene step that can help to maintain the NRT. A previous systematic review has confirmed that brushing and flossing can significantly reduce plaque and gingivitis as compared with tooth brushing alone. ${ }^{14}$

It is the presence of dental plaque and food debris in the crevices between the teeth that encourage bacteria to flourish, activating the inflammatory response and the innate immune system in the human body. These bacteria induce swelling and bleeding of the gums, the destruction of periodontal tissues and alveolar bones 
and the promotion of tooth mobility, thus ultimately causing tooth loss. ${ }^{34} 35$ The findings from some systematic reviews suggest that oral hygiene methods, such as tooth brushing, dental flossing and/or interdental brushing are all effective means of eliminating the periodontal pathogens thriving in the buccal cavity ${ }^{1436}$ and even in the blood. ${ }^{37}$

However, people with disabilities may have difficulties flossing, due to disability-related issues with self-control, movement coordination, comprehension and so on, although nearly $90 \%$ of them in this study were categorised as having basic self-care ability in terms of ADL. Adopting a habit of dental flossing, and accuracy and thoroughness of dental cleaning processes, may even be demanding for some non-disabled people, as well as for adults with disabilities. The assistance of interdental brushing, which is recognised as an easier and more effective method for reducing peridontal pathogens, ${ }^{36}$ can also be considered as an alternative approach.

To address the problem of NRT $<20$, oral hygiene instruction, a commonly used clinical technique, is imperative for improving oral hygiene. Since disabled adults may not cope with regular dental visits and examinations, integration of preventive and corrective oral health in their lives is highly beneficial. ${ }^{31}$ Routine daily teeth cleaning is undoubtedly the most economic and convenient approach to ensure oral health. It can also reduce the fear of individuals with disabilities about accessing oral health services and even shorten the scaling time required. ${ }^{38}$ Unfortunately, previous studies have demonstrated that community-dwelling individuals with disabilities have worse oral health than those living in institutions. ${ }^{22}{ }^{39}$ Since these participants were living at home with relatives, their families were generally more concerned with physiological diseases than with oral conditions and were not aware of the importance of oral hygiene. Teeth cleaning was also typically perceived as the individuals' own responsibility, as these disabled people generally seemed to be capable of managing the task. However, they had a higher prevalence of an NRT $<20$, which may imply that even if the participants had basic self-care ability, it does not mean that they are capable of achieving good quality oral hygiene. Their families sometimes opted to ignore these 'trivial' matters, as they were already exhausted by the burden of care. Consequently, without professional guidance and tracking, daily cleaning of the teeth becomes a difficult task for community-based people with disabilities. A systematic review has concluded that additional oral hygiene instruction could help cultivate a higher quality of oral health behaviours, thus ameliorating gingivitis and eradicating dental plaque. ${ }^{32}$

As many researchers claim that good oral health can improve almost every aspect of life, from overall health to self-esteem, communication, nutrition, quality of life, savings in medical expenses and finding employment, for people with disabilities, in addition to relieving the burden on their caregivers. ${ }^{170}$ To achieve the oral health goal of $8020,{ }^{3}$ more resources and attention should be invested to provide good oral care, matched to the individual's disability characteristics. Further integration of the social welfare networks, oral hygiene instructions and coordination of medical professionals and caregivers for adults with disabilities are recommended.

\section{Limitations}

This study has some limitations. First, the participants' oral conditions were examined by research assistants, rather than by qualified dentists, due to constraints on the participants' cooperation and expectations. Only superficial features, such as the remaining number of natural and filled teeth were investigated; other thorough evaluations, such as those of caries and periodontal tissues, were not performed. Thus, potential oral problems may have been ignored or underestimated by the NRT figures reported here. Second, some selection bias may have been involved as the criteria for inclusion included the ability to travel from home to the nearby school where the examinations were conducted. The participants were mostly categorised as having mild disabilities, with limited variation. Their oral health conditions should thus be presumed to be generally better than those of individuals with more severe disabilities, ${ }^{27}$ who were not included in this survey. The real situation of oral health for adults with disabilities may thus be even worse than that indicated by this study. Third, the self-reporting health behaviours questionnaire might trigger socially desired behaviours from participants implicitly directed by the research and/or researchers. Fourth, the participants were conveniently recruited from one location, rather than by nationwide cluster sampling. The generalisability of the study results may therefore be limited. Finally, the cross-sectional study design has an inherent limitation in terms of investigating the causal inferences between variables. As it is a snapshot of a specific moment, the cross-sectional design did not track variables over a period of time to gain insight into the process. To address this limitation, we asked participants to recall their oral health behaviour over the past year and/or when they were dentate. However, the recall process might generate another bias due to poor memory recall.

\section{CONCLUSION}

For community-dwelling individuals with disabilities, the prevalence of an NRT $<20$ and edentulism were significantly greater than that reported in previous studies. Poor oral hygiene behaviours were identified as being a general characteristic of the participants. Adults with intellectual disability had a greater likelihood of tooth loss. The other two modifiable factors strongly associated with an NRT $<20$ were the habit of seldom using dental floss and hypertension. As oral hygiene instructions are the least expensive and easiest way of integrating preventative intervention options 
for chronic diseases into daily activities, professionals should concentrate on this approach for individuals with disabilities and attempt to enhance their teeth cleaning awareness and capabilities. Finally, to satisfy the oral health needs of community-dwelling adults with disabilities, issues such as the risk factors associated with different types of disabilities, regular dental visits and their special needs can be further explored.

Acknowledgements We thank all participants in this study and staff at the Chiayi Bureau of Health Promotion for their support, which made this study possible.

Contributors M-YP and T-CH: designing the study, collecting and analysing data and drafting the paper. H-CT, M-SL and Y-CL: proof-reading and revising the manuscripts. $\mathrm{M}-\mathrm{YC}$ : initialising, conceptualising and supervising the research process.

Funding The study was supported by a grant from Chang Gung Memorial Hospital (BMRP 148).

Competing interests None declared.

Patient consent Obtained.

Ethics approval This study was approved by the institutional review board of the ethical committee of Chang Gung Memorial Hospital (IRB 102-3331B).

Provenance and peer review Not commissioned; externally peer reviewed. Data sharing statement № additional data are available.

Open Access This is an Open Access article distributed in accordance with the Creative Commons Attribution Non Commercial (CC BY-NC 4.0) license, which permits others to distribute, remix, adapt, build upon this work non-commercially, and license their derivative works on different terms, provided the original work is properly cited and the use is non-commercial. See: http://creativecommons.org/ licenses/by-nc/4.0/

(c) Article author(s) (or their employer(s) unless otherwise stated in the text of the article) 2017. All rights reserved. No commercial use is permitted unless otherwise expressly granted.

\section{REFERENCES}

1. Wang TF, Chen YY, Liou YM, et al. Investigating tooth loss and associated factors among older Taiwanese adults. Arch Gerontol Geriatr 2014;58:446-53.

2. Leroy R, Declerck D. Objective and subjective oral health care needs among adults with various disabilities. Clin Oral Investig 2013;17:1869-78.

3. Yamanaka K, Nakagaki H, Morita I, et al. Comparison of the health condition between the 8020 achievers and the 8020 non-achievers. Int Dent $J$ 2008;58:146-50.

4. Marcenes W, Kassebaum NJ, Bernabé E, et al. Global burden of oral conditions in 1990-2010: a systematic analysis. J Dent Res 2013;92:592-7.

5. Linden GJ, Lyons A, Scannapieco FA. Periodontal systemic associations: review of the evidence. J Clin Periodontol 2013;40(Suppl 14):S8-19.

6. Hayasaka K, Tomata Y, Aida J, et al. Tooth loss and mortality in elderly Japanese adults: effect of oral care. J Am Geriatr Soc 2013;61:815-20.

7. Huang JC, Peng YS, Fan JY, et al. Factors associated with numbers of remaining teeth among type 2 diabetes: a cross-sectional study. $J$ Clin Nurs 2013;22:1926-32.

8. Hsu KJ, Yen YY, Lan SJ, et al. Impact of oral health behaviours and oral habits on the number of remaining teeth in older Taiwanese dentate adults. Oral Health Prev Dent 2013;11:121-30.

9. Mac Giolla Phadraig C, McCallion P, Cleary E, et al. Total tooth loss and complete denture use in older adults with intellectual disabilities in Ireland. J Public Health Dent 2015;75:101-8.

10. Tsai SJ, Lin MS, Chiu WN, et al. Factors associated with having less than 20 natural teeth in rural adults: a cross-sectional study. BMC Oral Health 2015;15:158.

11. Jiang Y, Okoro CA, Oh J, et al. Sociodemographic and health-related risk factors associated with tooth loss among adults in Rhode Island. Prev Chronic Dis 2013;10:E45.
12. Bachkati $\mathrm{KH}$, Mortensen EL, Hansen HB, et al. Poor oral health in late life: selected predictors and initiatives towards prevention of tooth loss. J Gerontol Geriatr Res 2017;06:398.

13. Yoshino K, Ito K, Kuroda M, et al. Tooth Loss in Problem-oriented, Irregular, and Regular Attenders at Dental Offices. Bull Tokyo Dent Coll 2016;57:11-19.

14. Sambunjak D, Nickerson JW, Poklepovic T, et al. Flossing for the management of periodontal diseases and dental caries in adults. Cochrane Database Syst Rev 2011;12:CD008829.

15. Islas-Granillo H, Borges-Yañez A, Medina-Solis CE, et al. Tooth-Loss Experience and Associated Variables among Adult Mexicans 60 Years and Older. P R Health Sci J 2016;35:88-92.

16. Armour BS, Swanson M, Waldman HB, et al. A profile of state-level differences in the oral health of people with and without disabilities, in the U.S, in 2004. Public Health Rep 2008;123:67-75.

17. Hall JP, Chapman SL, Kurth NK. Poor oral health as an obstacle to employment for Medicaid beneficiaries with disabilities. J Public Health Dent 2013;73:79-82.

18. Oliveira JS, Prado Júnior RR, de Sousa Lima KR, et al. Intellectual disability and impact on oral health: a paired study. Spec Care Dentist 2013;33:262-8.

19. Ameer N, Palaparthi R, Neerudu M, et al. Oral hygiene and periodontal status of teenagers with special needs in the district of Nalgonda, India. J Indian Soc Periodontol 2012;16:421-5.

20. Cumella S, Ransford N, Lyons J, et al. Needs for oral care among people with intellectual disability not in contact with Community Dental Services. J Intellect Disabil Res 2000;44:45-52.

21. Anders PL, Davis EL. Oral health of patients with intellectual disabilities: a systematic review. Spec Care Dentist 2010;30:110-7.

22. Morgan JP, Minihan PM, Stark PC, et al. The oral health status of 4,732 adults with intellectual and developmental disabilities. J Am Dent Assoc 2012;143:838-46.

23. Turner S, Sweeney M, Kennedy C, et al. The oral health of people with intellectual disability participating in the UK Special Olympics. J Intellect Disabil Res 2008;52:29-36.

24. Havercamp SM, Scott HM. National health surveillance of adults with disabilities, adults with intellectual and developmental disabilities, and adults with no disabilities. Disabil Health J 2015;8:165-72.

25. World Health Organization. Disabilities. http://www.who.int/topics/ disabilities/en/ (accessed 28 Dec 2016)

26. Ministry of Health and Welfare, Taiwan. Statistics of General Health and Welfare. http://www.mohw.gov.tw/EN/Ministry/Statistic.aspx?f list_no=474 (accessed 28 Jan 2017).

27. Lai HT, Kung PT, Su HP, et al. Examining related influential factors for dental calculus scaling utilization among people with disabilities in Taiwan, a nationwide population-based study. Res Dev Disabil 2014;35:2231-40.

28. National Health Insurance Administration (NHI), Taiwan. Medical services, assistances \& cares. http://www.nhi.gov.tw/English/index. aspx?menu=8\&menu_id=30\&webdata_id=0\&WD_ID=30 (accessed 5 Apr 2017).

29. Steele JG, Treasure E, Pitts NB, et al. Total tooth loss in the United Kingdom in 1998 and implications for the future. Br Dent $J$ 2000;189:598-603.

30. Health Administration Promotion, Ministry of Health and Welfare. Survey on the prevalence of hypertension. hyperglycemia and hyperlipidemia in Taiwan http://www.hpa.gov.tw/BHPNet/Web/ HealthTopic/Topic.aspx?id=201409290001 (accessed 28 Jan 2017).

31. Gabre P, Martinsson T, Gahnberg L. Longitudinal study of dental caries, tooth mortality and interproximal bone loss in adults with intellectual disability. Eur J Oral Sci 2001;109:20-6.

32. Worthington HV, Clarkson JE, Bryan G, et al. Routine scale and polish for periodontal health in adults. Cochrane Database Syst Rev 2013;11:CD004625

33. Lindsay P. Care of the Adult with Intellectual Disability in Primary Care. London, UK: Radcliffe Pub, 2011.

34. Di Benedetto A, Gigante I, Colucci S, et al. Periodontal disease: linking the primary inflammation to bone loss. Clin Dev Immunol 2013;2013:1-7.

35. Graves DT, Li J, Cochran DL. Inflammation and uncoupling as mechanisms of periodontal bone loss. J Dent Res 2011;90:143-53.

36. Poklepovic T, Worthington HV, Johnson TM, et al. Interdental brushing for the prevention and control of periodontal diseases and dental caries in adults. Cochrane Database Syst Rev 2013;12:Cd009857.

37. Marín MJ, Figuero E, González I, et al. Comparison of the detection of periodontal pathogens in bacteraemia after tooth brushing by culture and molecular techniques. Med Oral Patol Oral Cir Bucal 2016;21:e276-84. 
38. Kim MJ, Noh H, Oh HY. Efficiency of professional tooth brushing before ultrasonic scaling. Int J Dent Hyg 2015;13:125-31.

39. Bershadsky J, Kane RL. Place of residence affects routine dental care in the intellectually and developmentally disabled adult population on Medicaid. Health Serv Res 2010;45:1376-89.
40. Elliott I, Nunn J, Sadlier D. Oral health \& disability: the way forward Ireland: National Disability Authority, 2005. http://nda.ie/ImageLibrary/PDF-Downloads/PDF-Version-Oral-Health-The-WayForward-939-KB-.pdf (accessed 10 Aug 2016). 